\title{
Structural Study of Liquidity: Relative Liquidity Excess with Chinese Characteristics
}

\author{
Panjia Chen ${ }^{1, a^{*}}$ \\ ${ }^{1}$ Shanghai University, No.99 Shangda Road, Baoshan District, Shanghai, China \\ a502298673@qq.com
}

\begin{abstract}
Keywords: Excess liquidity; Money gaps; Econometrical model; Unbalanced development of economy; Excess productivity
\end{abstract}

\begin{abstract}
A common idea of excess liquidity in the academia is that, too much money which should be used for GDP growth instead of causing excess productivity come into the capital market and the real estate market, and therefore, lead to series problems in the good market, labor market, capital market, exchange market, etc. This paper tried to set up a econometrical model on the basis of qualitative analysis, and found out too much deposit of enterprises, excess productivity caused by excess investment of some industries and the gradually increased differences between bank deposit and credit would increase excess liquidity further, and the development of tertiary will help to sooth the problem of excess liquidity. The deposit of the government and investment of real estate and state-owned enterprises will have both positive and negative effects to liquidity. In the background of unbalanced economic development, the level of both effects need more researches. Unbalanced economic and district development, imperfect economic institution and macro-policy, unfair distribution of payments are the fundamental reasons of and resolvents for excess liquidity.
\end{abstract}

\section{Introduction}

On the domestic and foreign academic circles, we can seek the multi-angle explanation for the fluidity. In Keynes's liquidity preference theory, liquidity is the ability of assets to realize at any time, usually the highest liquidity of money. Now, liquidity has been given a richer meaning, such as the ability of banks to meet customer needs such as deposit withdrawals at any time, and the ability of micro-entities to liquidate or finance assets without damage. For example, the liquidity of assets that are about to mature has increased, and so on. Therefore, a lot of related concepts have emerged from the excess liquidity, such as bank liquidity surplus, market liquidity surplus, macroeconomic liquidity surplus and so on.

Excess liquidity has always been an important problem besetting China's economy[1]. In particular, the outbreak of the financial crisis in 2008 made the world economic situation depressed. In order to cope with the crisis, governments of various countries resumed their own economies as soon as possible. Quantitative easing (QE) monetary policy has been introduced one after another. But the excess liquidity in China appears to be far worse than in other countries. With the introduction of the 4 trillion rescue plan in 2009, China's market is flooded with richer liquidity after the financial crisis, and the gap between deposits and loans is widening. By the end of March 2013, the total amount of M2 in China had broken through the 100 trillion mark and reached 103.6 trillion yuan. By the end of 2013, the total amount of M2 in China had reached 11 billion. Excess liquidity has brought inflation back into the spotlight[2].

\section{The Problem and Cause of Excess Liquidity}

The problem of excess liquidity. In our country until the second half of 2007, the economy has been growing at an unprecedented high level for several years, and low inflation is running at a low fever. Due to the abundant money supply caused by a large amount of foreign exchange, it has not caused the general rise in prices, and has produced "excess liquidity" in this particular state of our country. 
The price inflation of the long-term capital market, the house price and the stock market rise, the liquidity surplus is proving its power unceasingly to the people. Excessive short-term capital chasing long-term capital causes bubbles of long-term assets to rise, leading to a bubble economy. Mainly for real estate and related construction and other industries and stock market inflation. BA[3] believes that a prominent manifestation of excess liquidity is the rapid rise in asset prices.

Excess liquidity creates excess liquidity in financial markets, driving down interbank lending rates before banks invest money in profitable projects, such as "idle arbitrage". Then through the inter-bank market financing to meet the reserve assessment, which will lead to a sudden increase in the demand for funds in the inter-bank market, and thus lead to a "cash shortage" phenomenon[4].

In addition, small and medium-sized enterprises (SMEs) and enterprises in remote areas face difficulties in obtaining loans. But some other enterprises obtain the fund the environment to be relatively loose, namely has the liquidity surplus, causes the easy loan enterprise to invest too fast, the inventory increases, then causes the overcapacity and the economic partial overheating.

The cause of excess liquidity. Excess liquidity generally means that the supply-saving and demand-investment of capital cannot be matched effectively[5]. For an open economy, It can also be described as the contradiction between the gap between savings and investment and foreign trade in China in recent years. This kind of supply and demand does not deserve to have the absolute quantity mismatch also has the reason which the relative structure asymmetry, this kind of relative surplus includes the economy in the space and the time relative surplus. In general, according to the economic balance formula, savings $=$ investment, in China, savings exceed investment, according to the nature of excess liquidity, as we have previously analyzed, it is easy to generate excess liquidity due to the expansion of the difference between deposits and loans. Of course, it is necessary to point out that the problem of excess liquidity does exist, but not underinvestment[6].

The imbalance of financial market structure and the narrow investment channel are the basic reasons. He[7]held that there are a series of structural contradictions in China's financial sector, such as the singleness of financial products, while Sun[8]believes that too few investment channels have led to abnormal growth of savings deposits, and that there is a backlog of money in the money market. The capital market is short of funds and it is difficult to circulate funds between the two markets. While the difference between bank deposits and loans is too large, many social capital demands can't be effectively met. Excessive bank credit leads to overheating of investment and overcapacity of enterprises, while the unbalanced credit structure of banks results in the widening of the internal deposit and loan gap of banks. The existence of these structural problems fully shows that there are serious structural contradictions in the financial system of our country, which makes the social capital supply structure and the social capital demand structure very unsuitable, and then leads to the excess liquidity of the society.

Imperfect macro-control system is the essential reason. Zhu[9] thought: (1) the control tool lacks. Due to the lagging development of the national debt market, the open market operation currently plays a limited role in macroeconomic regulation and control in our country. Under the impact of increasing base money (mainly due to the rapid increase in foreign exchange holdings), the central bank had to issue a large number of central bank bills to replace the positive repo operation of treasury bonds. Under the pressure of financial costs, it is difficult for the central bank to sterilize excess market liquidity by relying solely on central bank bills. (2) the regulation and control policy has not been applied accurately and timely. For example, the low interest rate policy has aggravated the excess liquidity, but the overall low interest rate market environment has not been changed in time. (3) there are some defects in the policy transmission mechanism. There is a "leakage" effect in the transmission of monetary policy. A large amount of money is not transmitted and applied to the real economy, such as production, circulation and consumption, but "leakage" to the stock market and the banking system. When the economic situation improves, these "leaky" currencies will flow back out through the stock market and the banking system, resulting in excess liquidity in the market. 


\section{Excess liquidity Model and empirical Analysis}

Parameter setting. At present, there are four methods to measure excess liquidity: price gap method, real money gap method, nominal money gap method, money surplus method[10].

According to the money quantity theory, the money stock is equal to the nominal transaction volume divided by the velocity of money in the economy, and the currency circulation is generally a constant, that is, there will be no big change in the short term. So the increase in money supply (M2) in a year should be equal to the increment in real economy (GDP) and the increase in prices (CPI) in that year, expressed by formula:

\section{$\Delta \mathrm{M} 2=\Delta \mathrm{GDP}+\Delta \mathrm{CPI}$}

When $\Delta \mathrm{M} 2>\Delta \mathrm{GDP}+\Delta \mathrm{CPI}$, there is an excess supply of money, which is the bane of excess liquidity. Economists at the European Central Bank, in turn, call it a "currency gap". Although the "money gap" is large, it still needs long-term cumulative requirements and explicit requirements, that is, short-term concentrated outbreak of excess money, in order to show excess liquidity. However, in view of this indicator is more suitable to be included in the model, here we choose the "currency gap" as an indicator.

According to the previous analysis of the causes of excess liquidity, we selected several indicators, Foreign exchange accounts for (ex), Enterprise savings (ent_d), Government savings (gov_d), Secondary Industrial output (gdp2), Tertiary Industry output (gdp3), Housing Investment completion (house), State-Owned Investment completion (st_own), Investment completion (inv), one-year deposit interest rate (i). With the exception of interest rates, we have selected the year-on-year growth rates for this year and last year for each indicator.

Data sources and processing. All the data came from the websites of central banks and the National Bureau of Statistics, as well as from the monthly Financial and Statistics Bulletin. The data interval is based on the excess liquidity in the second half of 2003, which is generally considered by academic circles, and selects the data from January 2003 to December 2007. Residential investment completion (house), state-owned and state-controlled investment completion (st_own), investment completion (inv) December 2007 data has not yet been published, the default treatment.

Monthly gross domestic product (GDP) and secondary and tertiary industrial output are based on quarterly data, assuming that the economic growth rate remains the same in the months between quarters, and extrapolating the values for each month. Excess liquidity index (Li1=M2 growth rate-GDP growth rate over the same period).

The growth rate of foreign exchange accounts is calculated in RMB units over the same period of last year.

The model is established by Eviews. 
Model.

Table 1 Prediction results

Dependent Variable: LI1

Method: Least Squares

Sample (adjusted): 2003M01 2007M11

Included observations: 59 after adjustments

\begin{tabular}{|c|r|r|r|r|}
\hline Variable & \multicolumn{1}{c|}{ Coefficient } & Std. Error & \multicolumn{1}{c|}{ t-Statistic } & \multicolumn{1}{c|}{ Prob. } \\
\hline CNT_D & -0.019970 & 0.028272 & -0.706341 & 0.4833 \\
\hline HOUSE & 0.151246 & 0.060036 & 2.519244 & 0.0150 \\
\hline ST_OWN & -0.183987 & 0.044348 & -4.148720 & 0.0001 \\
\hline INV & -0.058124 & 0.016930 & -3.433266 & 0.0012 \\
\hline GDP2 & 0.343460 & 0.057047 & 6.020667 & 0.0000 \\
\hline GDP3 & 0.659262 & 0.208803 & 3.157337 & 0.0027 \\
\hline I & -0.809375 & 0.132701 & -6.099245 & 0.0000 \\
\hline GOV_D & 1.207528 & 0.513017 & 2.353777 & 0.0226 \\
\hline R-squared & -0.033878 & 0.011794 & -2.872349 & 0.0060 \\
\hline Adjusted R-squared & 0.901730 & Mean dependent var & 0.073791 \\
\hline S.E. of regression & 0.886007 & S.D. dependent var & 0.025476 \\
\hline Sum squared resid & 0.008601 & Akaike info criterion & -6.534213 \\
\hline Log likelihood & 0.003699 & Schwarz criterion & -6.217301 \\
\hline Durbin-Watson stat & 201.7593 & F-statistic & 57.35053 \\
\hline
\end{tabular}

Since the growth rate of each variable is selected in the model, the auto-correlation and multi-collinear problems of variables are effectively excluded. According to the results of the model, several variables basically explain $89 \%$ excess liquidity. This is reflected in the research of many scholars, which also reflects that the current excess liquidity in China is the result of long-term macroeconomic operation, is caused by the long-term imbalance of economic structure, in a short period of time it is difficult to completely "cure".

Results. According to the model, it can be seen that the continuous growth of corporate savings is indeed a major cause of excess liquidity, and the growth of investment completion and output value of the secondary industry has aggravated the excess liquidity. It just shows that excess capacity and excess liquidity are mutually reinforcing to a certain extent. The rising deposit interest rate increases the possibility of the expansion of the deposit and loan gap, further restrains consumer consumption, and makes the excess liquidity more serious.

What needs attention is that the increase of the output value of the tertiary industry will help to alleviate the excess liquidity, which is consistent with our previous analysis. The tertiary industry is mainly a consumer and service industry for residents. The development of the tertiary industry is conducive to alleviating overcapacity, to the development of deep and remote areas of the economy, and to the balance of economic development. At the same time, it is beneficial to increase employment and solve the problem of people's income and livelihood security. Only in this way can we really solve the problem of excess liquidity.

\section{Conclusion}

Excess liquidity is the result of long-term accumulation of capital in the economy, and the current excess liquidity is bound to be caused by irrational related economic systems and systems that have accumulated over a long period of time in our country. Balance is the right way to solve the problem of excess liquidity. 
Enhance the internal value of financial assets, expand the capital capacity of the market, prevent excess liquidity resulting in asset price inflation and the emergence of asset bubbles. Developing financial derivatives, improving the marginal income of the use of funds and solving the problem of excessive proportion of credit assets. In the long run, the absorption of liquidity can only be released through inflation and asset appreciation[11]. However, inflation has a huge negative impact on the entire economic development and social stability, so the gradual increase in asset value is more reasonable.

\section{References}

[1]X.F. Yang: From Excess Liquidity to Liquidity Crisis, World Economic Research, (2014) No. 5, p.16.(In Chinese)

[2]B. Yan: Inflation Effect of Excess Liquidity in China, (MS., Northeast University of Finance and Economics, China 2014). (In Chinese)

[3]S.S BA: An international perspective on excess liquidity, Finance of China, (2007) No. 20, p.42. (In Chinese)

[4]G. Yang and P.Y Sun: Whether Excess Liquidity Causes Money Shortage: An Analysis Based on Heterogeneous DSGE Framework, Economic Research in Nankai (2015) No. 05, p.59. (In Chinese)

[5] J. Luo and C. Zhong: A Study on Excess Liquidity in China, Macroeconomic Research, (2012) No. 11, p.18. (In Chinese)

[6]S.L Wu: Analysis of Main Causes of Excess Liquidity and Countermeasures, Western Finance, (2007) No. 10, p.73. (In Chinese)

[7]Z.Z He: It is Necessary to Adjust the Structure of Financial Market to Alleviate the Excess Liquidity, China Economic Times 2006-12-20 (007). (In Chinese)

[8]J.C. Sun: Analysis of Excess Liquidity of Commercial Banks Based on Macro, Science of Finance and Economics, (2006) No.07, p.1. (In Chinese)

[9]Q. Zhu: Unscramble Current Market Liquidity Surplus, Shanghai Economic Research, (2006) No. 10, p.13. (In Chinese)

[10]T. Gerdesmeier: Study on the Measurement Method of Excess Liquidity, Statistical study, (2007) No. 09, p.65.

[11]J. Wei and R. Wang: Excess liquidity in China: Dilemma and Choice, Economic Management ,(2007) No. 09, p.70. (In Chinese) 